\title{
Triple Band Dual Circular Slot Rectangular Microstrip Antenna
}

\author{
Dipali Gupta \\ Laxmi Narayan College of Technology, \\ Bhopal, India
}

\author{
Rajdeep Shrivastava \\ Laxmi Narayan College of Technology, \\ Bhopal, India
}

\begin{abstract}
This work focuses on design and analysis of microstrip patch antenna as well as effect of slots made on patch antenna to improve the bandwidth. A microstrip line fed, dual slot, triple band, rectangular microstrip patch antenna is designed. The designed antenna is most suited for $\mathrm{C}$ band, $\mathrm{X}$ band and $K_{U}$ band applications. The return loss is below $-10 \mathrm{~dB}$ in triple band with $1 \mathrm{GHz}$ bandwidth in the range $4.2 \mathrm{GHz}$ to $5.2 \mathrm{GHz}$, for second band with bandwidth $1.6 \mathrm{GHz}$ in the range $7.4 \mathrm{GHz}$ to $9 \mathrm{GHz}$, for third band with bandwidth $4 \mathrm{GHz}$ in the range of $10.6 \mathrm{GHz}$ to $14.6 \mathrm{GHz}$. The antenna is thin and compact which makes it portable. The VSWR parameter is found to be less than 2 within the operating frequency range. The antenna is designed and simulated on an air substrate with dielectric constant of unity and thickness of $1.6 \mathrm{~mm}$. The design is analysed by CST software based on Finite Element Method.
\end{abstract}

\section{Keywords}

Triple band antenna, Microstrip antenna, Slot antenna, Rectangular patch, $K_{U}$-band.

\section{INTRODUCTION}

The microstrip patch antennas are very commonly used and preferred in this modern era for their compatibility to be fit in Mobile, Aircraft, and Satellites owing to very small sizes. Antennas are designed and fabricated in various shapes and sizes. It operates in $\mathrm{C}$ band ( 4 to $8 \mathrm{GHz}$ ), $\mathrm{X}$ band 8 to $12 \mathrm{GHz}$ ) and $K_{U}$ band (12 to $18 \mathrm{GHz}$ ) which makes it suitable for long-distance radio telecommunications and satellite communications, radar, terrestrial broadband, space communications, amateur radio. Khidre et al. [1] designed a microstrip patch antenna for dual-band frequency operation. The antenna operates in $2-4.5 \mathrm{GHz}$ frequency range. The performance of this antenna is tunable at frequency range from 1.45 to 1.93 with a capacitance range from 0.31 to $0.74 p F$. B. Rana et al. [2,] designed a cylindrical dielectric resonator antenna (CDRA) fed by non-resonant microstrip patch [11] fabricated with FR-4 substrate. Antenna array is designed at the centre frequency of $9.04 \mathrm{GHz}$ for getting higher directive gain. The array offers an impedance bandwidth of $2.9 \%$. P.S. Bakariya et al. [3] designed a multiband corner-truncated rectangular patch with a rectangular slot microstrip antenna with a proximity-coupled feed fabricated using $0.8 \mathrm{~mm}$ thick FR4 substrate with dielectric constant 4.4 for operating in the $2300-2400 \mathrm{MHz}$, 2400-2485 MHz, 3.3-3.7 GHz, and 5.15-5.35 GHz, 5.725$5.825 \mathrm{GHz}$ bands. B. R. S Reddy et al. [4] designed a compact zigzag-dual $\mathrm{T}$-shaped slits on either sides of a rectangular microstrip patch with probe-fed and circular dumbbell defected ground structure for wireless applications. The antenna generates three separate resonances to cover both the 2.45/5.28-GHz WLAN bands \& the $3.5-\mathrm{GHz}$ WiMAX bands with a small overall size of $40 \times 28 \times 3.175 \mathrm{~mm}^{3}$. Z. H.
Zarghani et al. [5] designed a centre-fed single-layer, dualband reflect array antenna in which each element consists of a square ring and a patch with slots. It operates in two bands (X and $\mathrm{Ku}$ ) and used only one horn antenna as feed in a fixed position. Maximum gain of $23.4 \mathrm{~dB}$ at $8.2 \mathrm{GHz}$ with $33 \%$, 3$\mathrm{dB}$ bandwidth and $17 \%, 1-\mathrm{dB}$ bandwidth and a maximum gain of $25.7 \mathrm{~dB}$ at $13.2 \mathrm{GHz}$ with $30 \%, 3-\mathrm{dB}$ bandwidth and $14 \%, 1-\mathrm{dB}$ bandwidth is achieved. S Liu et al. [6] designed a single-patch single- layer four-band U-slot patch antenna, with linear polarization, for WiMAX and WLAN applications. Impedance bandwidths $(\mathrm{dB})$ of $2.1 \%, 3.3 \%, 7.1 \%$ and $5.0 \%$ were achieved at central frequencies $3.35 \mathrm{GHz}, 3.70 \mathrm{GHz}$, $5.20 \mathrm{GHz}$ and $5.80 \mathrm{GHz}$ respectively. This antenna is made by cutting four asymmetrical U-slots in the patch. Sekhar M et al. [7] designed a triple band circular ring patch antenna fed by small rectangular strip simulated on an FR4 substrate of $2 \mathrm{~mm}$ thickness. It is suitable for X-band, Ku-band and K-band applications due to its compact structure. The return losses obtained are $-35.80 \mathrm{~dB},-42.39 \mathrm{~dB}$, and $-44.98 \mathrm{~dB}$ at 8.96 $\mathrm{GHz}, 14.44 \mathrm{GHz}$ and $18.97 \mathrm{GHz}$ respectively. Kurmi et al. $[8,10]$ designed a coplanar circular patch monopole for wideband applications. The truncated patch [8] is used to reduce the weight of the patch without affecting the radiation field direction and its strength. Reddy [13] et al designed a defected ground based antenna with Zigzag-Shaped-Slit Microstrip patch WLAN and WiMAX applications. Rajat et al. [9] designed a dual band rectangular and circular slot loaded microstrip antenna for WLAN/GPS/WiMAX applications. The rectangular microstrip antenna is loaded by triple rectangular slot and dual circular slot. This slot loaded antenna provides dual frequency band. In first frequency band (1.29-1.67 GHz) the bandwidth of antenna is $25.675 \%$ and in second frequency band $(2.02-2.92 \mathrm{GHz})$ the bandwidth of antenna is $36.437 \%$. R Bargavi et al. [12] proposed a paper on compact triple band $\mathrm{H}$ - shaped slotted circular patch antenna. This paper provides an insight in the design of Microstrip antenna and presents a design of triple band $\mathrm{H}$ shaped slot Circular Patch Antenna. The design utilizes the circular patch of radius $20 \mathrm{~mm}$ and obtains triple band at the frequencies $2.4 \mathrm{GHz}, 4.5 \mathrm{GHz}$ and $6.5 \mathrm{GHz}$. The return loss was measured as $-25 \mathrm{~dB},-24 \mathrm{~dB},-15 \mathrm{~dB}$ and the gain obtained as $7 \mathrm{~dB}, 5 \mathrm{~dB}$ and $4.2 \mathrm{~dB}$ in the respective frequencies. The rest of the paper is arranged as follows. Section 2 consists of the design of proposed antenna, section 3 covers the result and section 4 covers the conclusion and future scope.

\section{ANTENNA DESIGN AND CONFIGURATION}

The proposed antenna design is a rectangular dual circular slot antenna as shown in Fig 1. The design is simple and the feed used is microstrip line. The dimensions of antenna are $30 \times 30 \times 1.6 \mathrm{~mm}^{3}$ used for the simulation. There are two 
circular slots in this patch and a rectangular cut at one corner to increase the bandwidth.

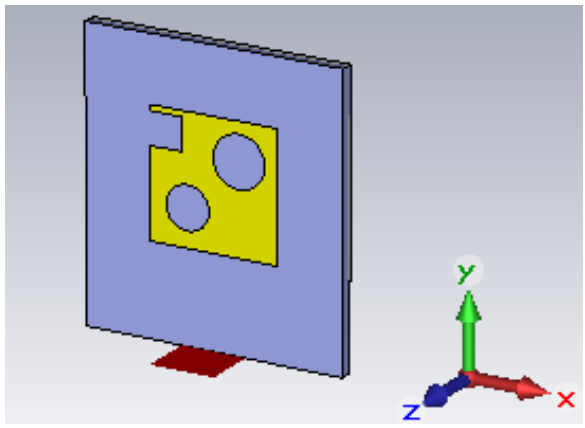

(a)

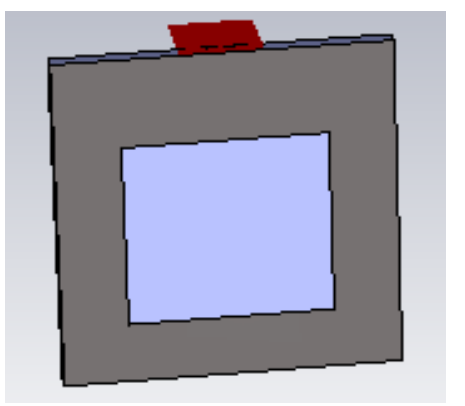

(b)

Figure 1 Front view (a) and rear view (b) of designed antenna

The one circular slot of radius $3 \mathrm{~mm}$ (D1=D2) is located at (3, 3 ) from the centre of patch and the other slot is also of same radius and located at $(-3,-3)$ from the centre of patch and a rectangular cut at the corner is of $15 \times 7.5 \mathrm{~mm}^{2}$ These two slots and a rectangular cut at one corner results in triple band formation and higher bandwidth.

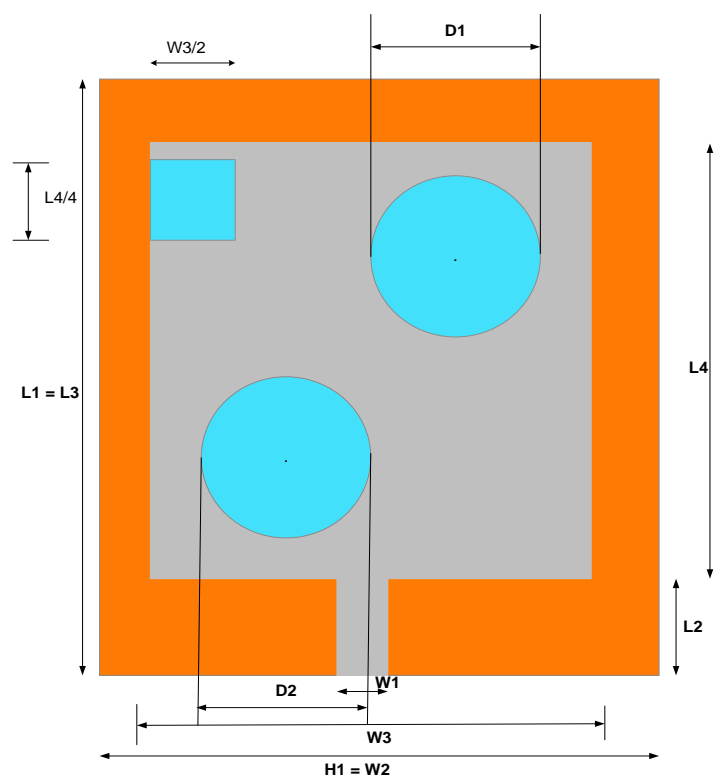

Figure 2 Geometry of the proposed antenna (Top view)
Table 1 Designed parameters of the proposed antenna

\begin{tabular}{|l|l|l|}
\hline Parameter & Value (mm) & Description \\
\hline L1 & 30 & Length of ground \\
\hline H1 & 30 & Height of ground \\
\hline L2 & 15 & Feed length \\
\hline W1 & 2.5 & Feed width \\
\hline T1 & 1.6 & Substrate thickness \\
\hline L3 & 30 & Substrate length \\
\hline W2 & 30 & Width of substrate \\
\hline L4 & 14.727 & Length of Patch \\
\hline W3 & 14.727 & Width of patch \\
\hline D1=D2 & 3 & Radius of slots \\
\hline
\end{tabular}

\section{RESULT}

In this project, CST MICROVAVE STUDIO 2015 software which is based on finite Integral Method (FIM) is used to design a Microstrip Patch Antenna. The S-parameter (return loss) of the proposed antenna is shown in the Fig. 3. It can be seen that the impedance bandwidth covers $\mathrm{C}$ band $(4-8)$ $\mathrm{GHz}, \mathrm{X}$-band (8 - 12) $\mathrm{GHz}$ and $\mathrm{Ku}$-band (12 - 18) $\mathrm{GHz}$ with centre frequencies of $4.71 \mathrm{GHz}, 7.96 \mathrm{GHz}$ and $12.94 \mathrm{GHz}$ and a return loss of $-14 \mathrm{~dB},-14 \mathrm{~dB},-34 \mathrm{Db}$ respectively.

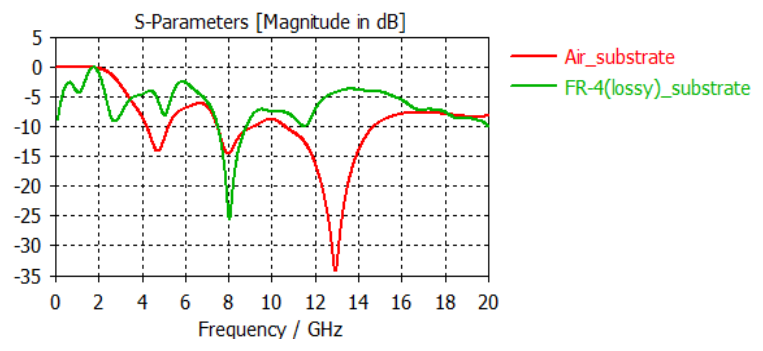

(a)

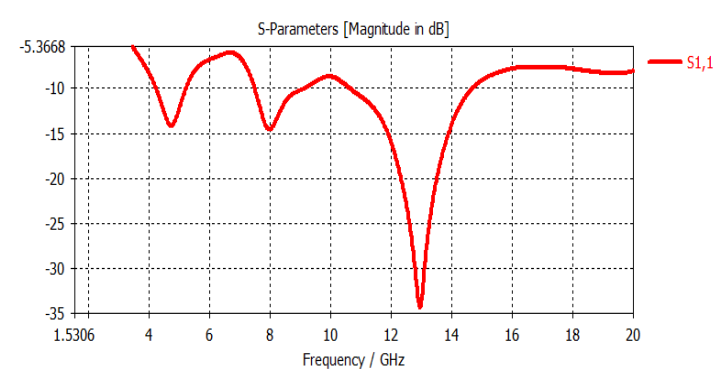

(b)

Figure 3 (a) Return loss comparison for two substrates Air and FR-4 (lossy) materials as substrate,

(b) Return loss for air substrate at resonant frequencies

The Voltage Standing Wave Ratio (VSWR) of the antenna at the centre frequencies $4.71 \mathrm{GHz}, 7.96 \mathrm{GHz}$ and $12.94 \mathrm{GHz}$ is $1.48,1.46$ and 1.04 respectively which represents that a good impedance matching is achieved and maximum power is transferred to the antenna is shown in the Fig. 4. 


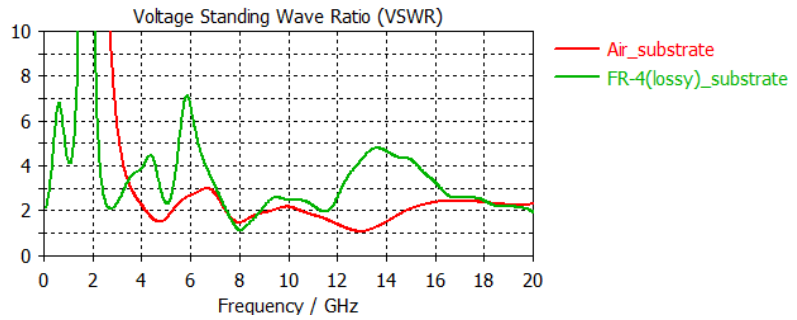

Figure 4 VSWR comparison for two substrates air and FR-4 (lossy) materials as substrate.

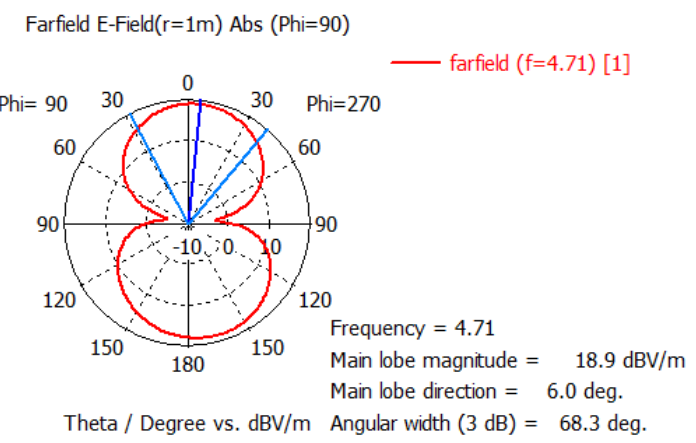

(a)

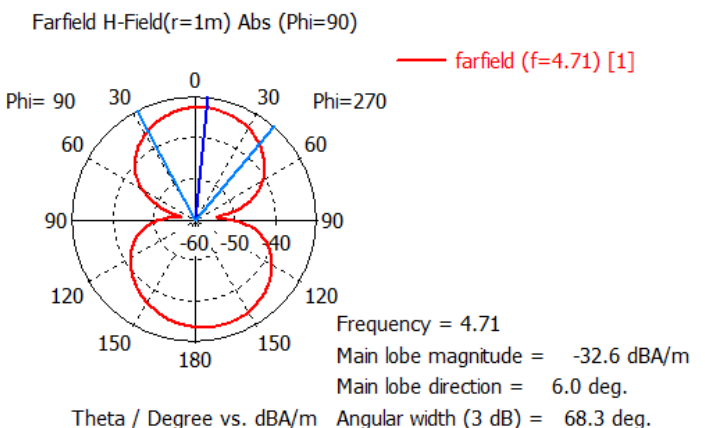

(b)

Figure 5 (a) Farfield E-field at 4.71 GHz, (b) Farfield Hfield at $4.71 \mathrm{GHz}$.

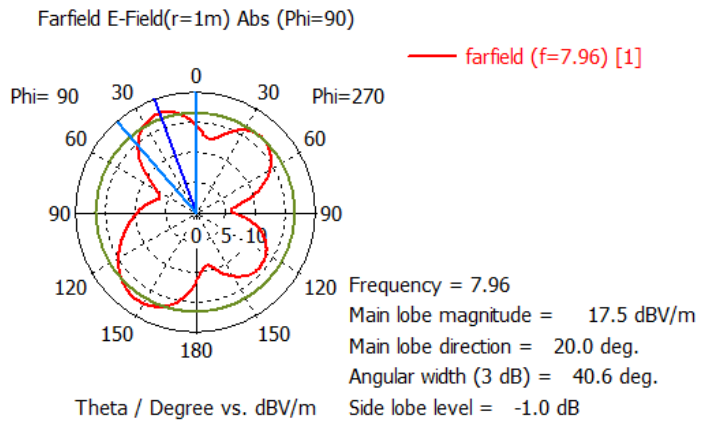

(a)

The radiation pattern (E-Plane and H-Plane) of the antenna at different resonating frequencies are shown in the Fig. 5, Fig. 6 and Fig. 7. It is observed that the proposed antenna is a bidirectional which is well suited for the wireless communication applications. The bidirectional behavior of the antenna is due to the the feeding micro-strip connecting all the radiating patch. The proposed antenna is providing a stable gain of $6.41 \mathrm{~dB}$ in the operational bandwidth centered around $12.94 \mathrm{GHz}$.

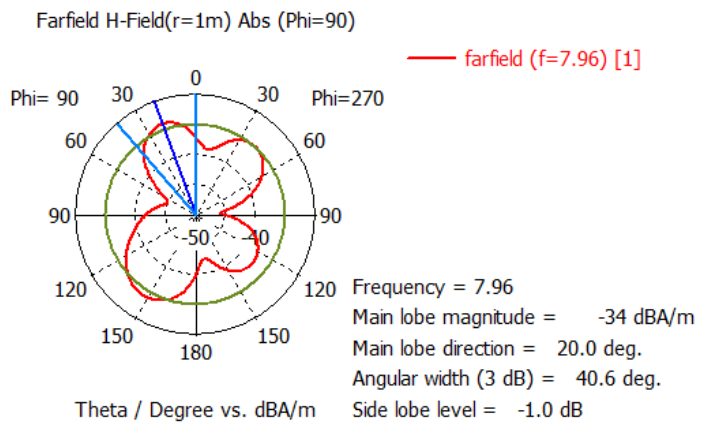

(b)

Figure 6 (a) Farfield E-field at 7.9 GHz, (b) Farfield Hfield at $7.9 \mathrm{GHz}$.

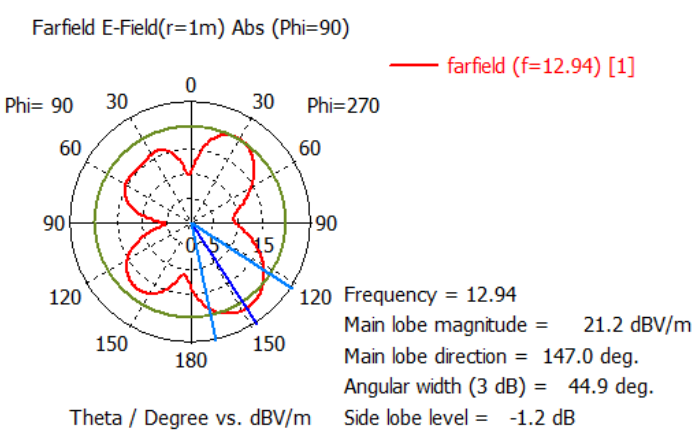

(a)

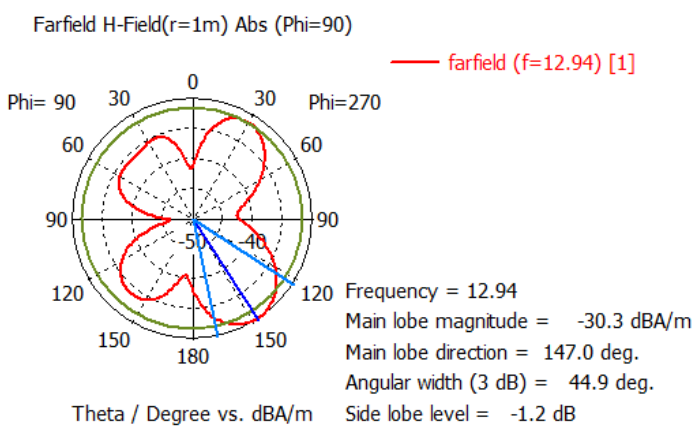

(b)

Figure 7 (a) Farfield E-field at 12.94 GHz, (b) Farfield Hfield at $12.94 \mathrm{GHz}$.

Table 2 Results of antenna with Triple band

\begin{tabular}{l|ll|l|}
\multicolumn{3}{|c}{ Parameter } & \multicolumn{3}{c}{ Centre Frequency } \\
\hline & $\mathbf{f 1}=4.71 \mathrm{GHz}$ & $\mathbf{f 2}=7.96 \mathrm{GHz}$ & $\mathbf{f 3}=12.94 \mathrm{GHz}$ \\
\hline S11 & $-14 \mathrm{~dB}$ & $-14 \mathrm{~dB}$ & $-34 \mathrm{~dB}$ \\
\hline VSWR & 1.49 & 1.46 & 1.04 \\
\hline GAIN & $4.24 \mathrm{~dB}$ & $2.91 \mathrm{~dB}$ & $2.82 \mathrm{~dB}$
\end{tabular}

\section{CONCLUSION \& FUTURE SCOPE}

A triple band dual circular slot rectangular patch antenna is presented in this paper. Structure of this antenna is simple and compact size of $30 \times 30 \times 1.6 \mathrm{~mm}^{3}$ which makes it easy to be incorporated in small devices. 


\section{CONCLUSION}

Results show that the frequency bandwidth covers $\mathrm{C}$ band (4 8) $\mathrm{GHz}, \mathrm{X}$-band $(8$ - 12) $\mathrm{GHz}$ and Ku-band $(12-18) \mathrm{GHz}$, at 4.71 GHz, $7.96 \mathrm{GHz}$ and $12.94 \mathrm{GHz}$. Results show good impedance matching, bidirectional radiation patterns in the operating band. Thus, this antenna is a good applicant for wireless communication applications which includes long distance radio telecommunications like cordless telephones, some Wi-Fi devices, weather radar systems, direct broadcast satellite.

\section{FUTURE SCOPE}

Simulation can be performed for various parameters such as gain, directivity, VSWR, impedance bandwidth of antenna for different size of antenna. Different combination of material can be used for substrate layer and modify thickness to increase the bandwidth of antenna. The antenna can also be manufactured for its result measurement and verification. Additionally, Defected ground structure is a new concept which has great scope in future development of microstrip patch antenna. DGS is very easy to implement as it does not involve any complexity. The antenna array [8] can be designed for the further work.

\section{REFERENCES}

[1] A. Khidre, F. Yang, and A. Z. Elsherbeni "A Patch Antenna with a Varactor -Loaded Slot for Reconfigurable Dual-Band Operation" IEEE Trans. on Antennas and Propagation, vol. 63, no. 2, Feb. 2015.

[2] B. Rana, and S. K. Parui, "Nonresonant Microstrip Patch-Fed Dielectric Resonator Antenna Array" IEEE Trans. on Antennas and Wireless Propagation Letters, vol. $14,2015$.

[3] P. S. Bakariya, S. Dwari, M. Sarkar and M. K. Mandal, "Proximity-Coupled Multiband Microstrip Antenna for Wireless Applications" IEEE Trans. on Antennas and Wireless Propagation Letters, vol. 14, 2015.

[4] B. R. S. Reddy and D. Vakula "Compact Zigzag-ShapedSlit Microstrip Antenna with Circular Defected Ground Structure for Wireless Applications" IEEE Trans. on Antennas and Wireless Propagation Letters, vol. 14, 2015.
[5] Z. H. Zarghani and Z. Atlasbaf, "A New Broadband Single-Layer Dual-Band Reflect array Antenna in X- and $\mathrm{Ku}$-Bands" IEEE trans. on Antennas and wireless Propagation Letters, vol. 14, 2015.

[6] S Liu, Shi-Shan Qi, Wen Wu, and Da-Gang Fang "Single-Layer Single-Patch Four-Band Asymmetrical USlot Patch Antenna" IEEE Trans. on Antennas and wireless Propagation Letters, vol. 62, no. 9, Sept 2014.

[7] M Sekhar, S. N. Bhavanam, P. Siddaiah "Triple Frequency Circular Patch Antenna" IEEE Trans. on International Conference on Computational Intelligence and Computing Research, vol. 14, 2014.

[8] Y. Kurmi, V. Chaurasia, and H. Kaptan, "Microstrip Planer Antenna Array by Proximity Fed for Complete S Band Applications". Under Processing in IEEE U. P. Section International Conference on Electrical, Computer and Electronics, 4-6 December, 2015.

[9] R. Srivastava, "Dual Band Rectangular and Circular Slot Loaded Microstrip Antenna for WLAN/GPS/WiMAX Applications" International Conference on Communication System and Network Technologies (CSNT), 2014.

[10] Y. Kurmi, and V. Chaurasia, "Coplanar Waveguide Fed Wideband Monopole Antenna for WIMAX Application" IJFT Vol. 1 No.1, 34-36, 2014.

[11] D. Gupta, A. Bhargava "A comparative Analysis of Nonresonant Microstrip Patch-Fed Dielectric Resonator Antenna and Proximity-Fed Annular Slot Antenna" International Journal of Computer Applications, Aug. 20, 2016.

[12] R. Bargavi, K. Sankar, S. A. Samson "Compact triple band H-shaped slotted Circular Patch Antenna" International Conference on Communications and Signal Processing (ICCSP), 2015.

[13] B. R. S. Reddy and D. Vakula, "Compact ZigzagShaped-Slit Microstrip Antenna with Circular Defected Ground Structure for Wireless Applications”, IEEE Antennas and Wireless Propagation Letters, vol. 14, 2015. 